\title{
Fictional responses from Vonesh et al.
}

\author{
Jaimie T. A. Dick - Mhairi E. Alexander • Anthony Ricciardi - Ciaran Laverty $\cdot$ Paul O. Downey \\ Meng Xu • Jonathan M. Jeschke • Wolf-Christian Saul • Matthew P. Hill • Ryan Wasserman • \\ Daniel Barrios-O'Neill • Olaf L. F. Weyl • Richard H. Shaw
}

Published online: 18 January 2017

(C) The Author(s) 2017. This article is published with open access at Springerlink.com

Vonesh et al. (2017) in their critique of Dick et al. (2017) erect a straw man with their thought experiment; they look for reasons why comparative functional response (CFR) might fail, when CFR clearly and repeatedly succeeds. We can view CFR as a hypothesis that posits "differences in magnitude, or shape, of invader/native FRs explain and predict invader ecological impact". We can test this hypothesis with a mini-meta-analysis: in 18 out of 22 study

J. T. A. Dick $(\varangle) \cdot$ C. Laverty · D. Barrios-O’Neill Institute for Global Food Security, School of Biological Sciences, Queen's University Belfast, Belfast BT9 7BL, Northern Ireland, UK

e-mail: j.dick@qub.ac.uk

C. Laverty

e-mail: claverty14@qub.ac.uk

D. Barrios-O’Neill

e-mail: danny_of_neill@yahoo.co.uk

M. E. Alexander

School of Science and Sport, University of the West of Scotland, Paisley, UK

e-mail: Mhairi.Alexander@uws.ac.uk

\section{A. Ricciardi}

Redpath Museum, McGill University, Montreal, QC H3A 0C4, Canada e-mail: tony.ricciardi@mcgill.ca

systems, and 39 of 47 individual CFR studies, FRs of known damaging invaders are significantly higher than FRs of native counterparts (Dick et al. in press). These systems consider 1-5 pairwise resource comparisons; large numbers are not needed for CFR to have high explanatory and predictive power (and practical utility in targeted studies). Vonesh et al. (2017) list reasons why CFR studies should fail: differing conversion efficiencies, mortality, interference, body size,

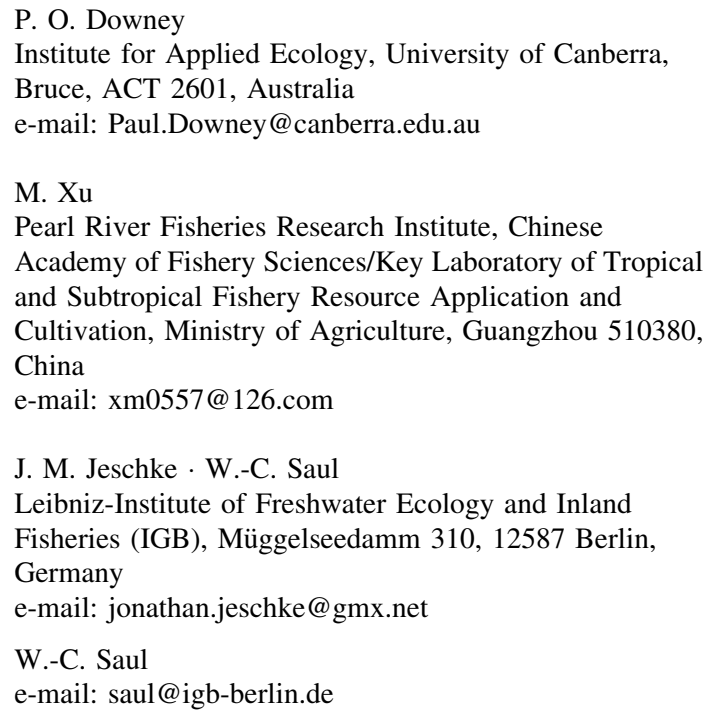


density-yet in the face of these (likely) differences, CFR remains highly predictive. We agree that refining CFR is desirable; this is achieved by incorporating relative invader:native abundances, a proxy for numerical responses, which captures differential conversion efficiencies, plus aggregative and reproductive responses (see Dick et al. in press). This improves the predictive capacity of CFR as, for example, relatively low invader per capita effects can be multiplied by relatively high abundances. CFR also provides mechanistic and predictive assessments applicable to emerging and potential invaders, specifically what invasion history and impact indices cannot achieve.

Finally, it is disappointing that Vonesh et al. (2017) ignored the true essence and thrust of Dick et al.'s advocacy, that CFR provides a testable hypothesis that can truly unify invasion ecology across taxonomic/ trophic groups and habitats. We thus finish with our own thought experiment: would the FR (with/without comparators) of any invasive species (actual or potential) be unmeasurable or uninformative?

Open Access This article is distributed under the terms of the Creative Commons Attribution 4.0 International License (http://

J. M. Jeschke - W.-C. Saul

Department of Biology, Chemistry Pharmacy, Institute of Biology, Freie Universität Berlin, Königin-Luise-Str. 1-3, 14195 Berlin, Germany

J. M. Jeschke - W.-C. Saul

Berlin-Brandenburg Institute of Advanced Biodiversity

Research (BBIB), Altensteinstr. 34, 14195 Berlin,

Germany

M. P. Hill

Centre for Invasion Biology, Stellenbosch University, Private Bag X1, Matieland 7602, South Africa

e-mail: matthill@protonmail.com

R. Wasserman · O. L. F. Weyl

South African Institute for Aquatic Biodiversity (SAIAB), P. Bag 1015, Grahamstown 6140, South Africa

e-mail: ryanwas21@gmail.com

O. L. F. Weyl

e-mail: O.Weyl@saiab.ac.za creativecommons.org/licenses/by/4.0/), which permits unrestricted use, distribution, and reproduction in any medium, provided you give appropriate credit to the original author(s) and the source, provide a link to the Creative Commons license, and indicate if changes were made.

\section{References}

Dick JTA, Laverty C, Lennon JJ, Barrios-O’Neill D, Mensink PJ, Britton JR, Medoc V, Boets P, Alexander ME, Taylor NG, Dunn AM, Hatcher MJ, Rosewarne PJ, Crookes S, MacIsaac HJ, Xu M, Ricciardi A, Wasserman RJ, Ellende, BR, Weyl OLF, Lucy FE, Banks PB, Dodd JA, MacNeil C, Penk MR, Aldridge DC, Caffrey JM. (in press) Invader relative impact potential: a new metric to understand and predict the ecological impacts of existing, emerging and future invasive alien species. J Appl Ecol (in press)

Dick JTA, Alexander ME, Ricciardi A, Laverty C, Downey PO, Xu M, Jeschke JM, Saul W-C, Hill MP, Wasserman R, Barrios-O'Neill D, Weyl OLF, Shaw RH (2017) Functional responses can unify invasion ecology. Biol Invasions. doi:10.1007/s10530-016-1355-3

Vonesh J, McCoy M, Altwegg R, Landi P, Measey J (2017) Functional responses can't unify invasion ecology. Biol Invasions. doi:10.1007/s10530-016-1356-2

R. Wasserman · O. L. F. Weyl

Centre for Invasion Biology, South African Institute for Aquatic Biodiversity (SAIAB), P. Bag 1015,

Grahamstown 6140, South Africa

R. H. Shaw

CABI UK, Bakeham Lane, Egham TW20 9TY, UK

e-mail: r.shaw@cabi.org 